\title{
EXTRA-GONADAL CHORIOCARCINOMA IN THE MALE
}

\author{
L. P. Holt*, M.B., M.R.C.P., D.C.H. \\ Medical Registrar.
}

\author{
D. H. Melcher, M. A. (Cantab.), M.B., \\ Ch.B. (Cape Town) \\ Assistant Pathologist.
}

\author{
J. Colquhoun**, M.B., F.F.R. \\ Senior Radiological Registrar. \\ Addenbrooke's Hospital and University Pathology Department, Cambridge.
}

Primary choriocarcinoma in the male is an uncommon tumour usually arising in the testis; extragonadal primary tumours are very rare. This is an account of an extragonadal choriocarcinoma, probably arising in the stomach, of a male patient.

\section{Case Report}

F.N. Male, aged 47 (Hospital No. 61178). He first attended in 1952, aged 37, complaining of recurrent dyspepsia. Radiological examination revealed a small gastric ulcer on the lesser curve of the stomach. He failed to keep his outpatient appointments and was not seen again until his admission in December, 1961 with hæmatemesis and melæna. On examination the only abnormality found was a liver edge palpable two finger breadths below the costal margin.

Investigations: $\mathrm{Hb}$. $12 \mathrm{~g} . / 100 \mathrm{ml}$., chest $\mathrm{X}$-ray and screening normal. Barium meal: scarring from an ulcer on the lesser curvature in the pre-pyloric region of the stomach.

He was discharged and failed to return until May, 1962 when his weight was noted to have fallen by $6 \frac{1}{2}$ lbs. $(3 \mathrm{Kg}$.). He then complained of pain in the epigastrium and in the centre of the back which awakened him in the middle of the night but had no definite relationship to food. He was not vomiting although he had flatulence and was constipated. Physical examination, including rectal examination, showed no abnormality. A provisional diagnosis of pancreatitis was made but his symptoms cleared and he again failed to keep his appointments.

He was not seen again until October, 1962 when he was re-admitted as an emergency again complaining of epigastric pain, especially after food, which occasionally went through to his back, and recurrent small hæmoptysis. He had noticed swelling of both legs and a lump in the left side of his neck.

On examination he was thin, having lost over 14 lbs. (6.2 $\mathrm{Kg}$.) during a period of ten months, and anæmic but not jaundiced. A lymph node the size of a walnut was noted in the left supraclavicular region. There was pronounced gynæcomastia, especially on the right side. He was tender in the epigastrium and an ill-defined mass, which moved on respiration, could be felt in the left hypochondrium.

*Present Address-Queen Elizabeth Hospital, Birmingham, England.

**Present Address-University Hospitals of Cleveland, Cleveland, Ohio, U.S.A.
Investigations: Hb. 5.6 g./100 ml., WBC. $13,000 \overrightarrow{\vec{\mu}}$ cu. mm. (82\% polys.), retics. $1.6 \%$, ESR $32 \mathrm{~mm}$. $/ \mathrm{hr}$ (Westergren), hypochromic-microcytic film. Urines contained a trace of albumin. Blood was not detectee in the fæces. Total serum protein $6.4 \mathrm{~g} .1100 \mathrm{ml}$. thymol turbidity 1 unit, zinc sulphate 2 units, serunf acid phosphatases $0.5 \mathrm{~K}$-A Units (N.R. 1.2-3.1), serum alkaline phosphatase 11.5 K-A Units (N.R. 3-11) A chest radiograph revealed numerous "cannon-ball" deposits in both lungs.

After admission the patient became confused and continued to complain of abdominal pain and shorto ness of breath. He was transfused with blood but became jaundiced and pyrexial and was therefore given chlorpromazine and antibiotics. His generat condition deteriorated, the ill-defined mass in the left hypochondrium increased in size and became tender and the jaundice increased until he eventuall died in coma, twenty days after admission.

Three days after admission an excretory-urogiam

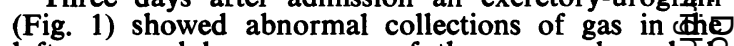
left upper abdomen; some of these were branchece suggesting that they were in the biliary ducts of the left lobe of the liver. Both kidneys were functioning well but the left one was displaced downward an laterally and both upper ureters were displace laterally, evidently by a retroperitoneal mass. There. was slight elongation of the upper major calyx o the left kidney, of doubtful significance. The liver was large. There was a diffuse density in the pelvis which suggested free peritoneal fluid.

Further X-ray examination of the abdomen was not possible for a further four days, by which time the patient was very ill and immobile. Agaif abnormal branching gas shadows were present in the left upper abdomen; a small quantity of Gastrografipa was given by mouth and it was evident that thes 8 gas shadows were in front of the stomach Unfortunately the patient's condition precluded proper examination of the stomach. The left dome of the diaphragm was noted to be elevated and immobile

Eleven days after admission a portable film of the chest showed extensive consolidation at the lef. lung base but little change in the metastases. Sevef్ days later an abdominal film (Fig. 2) showed a large gas-containing cavity in the left upper abdomert extending over the midline

\section{Pathology}

Necropsy (P62/601) Macroscopic: The body wa⿱ that of a pale, thin, emaciated adult male with pronounced enlargement of the breasts.

A large encapsulated mass of soft necrotic tissue $(25 \times 10 \times$ up to $8.0 \mathrm{~cm}$.) was present under the let. 


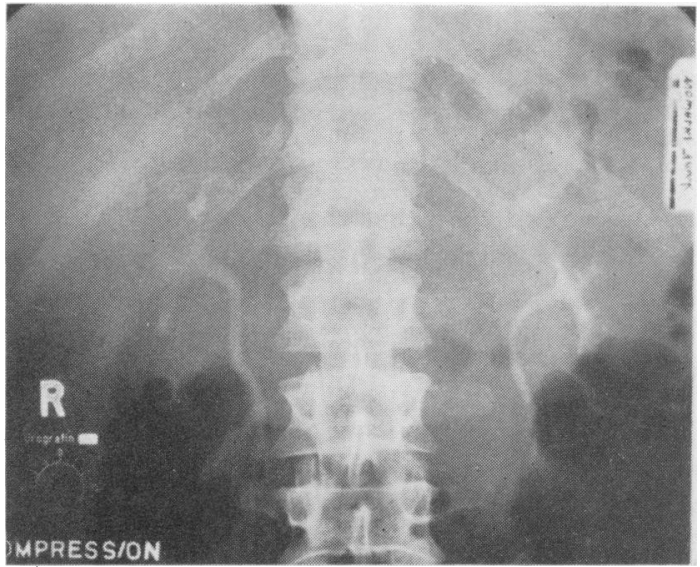

FIG. 1-Excreting pyelogram. Downward displacement of left kidney and deviation of ureters. Abnormal gas shadows.

side of the diaphragm. The anterior and superior walls were formed by the left lobe of the liver which was enlarged and red-brown in colour. The mass was bordered posteriorly by the anterior wall of the stomach, in which there was a large ulcer $(6 \mathrm{~cm}$. diam.) (Fig. 3) connecting the lumen of the stomach with the mass, and was also bordered by enlarged lymph nodes together with the middle third of the body of the pancreas. The inferior wall of the mass was formed by the transverse colon, mesocolon and greater omentum. The mass was completely sealed off from the peritoneum and appeared to lie mainly within the left lobe of the liver. Numerous discrete round lesions were present in the liver (the largest $5 \mathrm{~cm}$. in diameter), the majority consisting of a red hæmorrhagic periphery and a white, dry, centre. Some lesions were cystic and others had a thickwalled capsule and contained grey necrotic material The remainder of the alimentary system appeared normal; the ulcer on the lesser curve of the stomach, seen radiologically, was not found.

The left pleural cavity was almost completely obliterated by fibrous tissue; the right pleural cavity appeared normal. Numerous lesions similar to those seen in the liver were observed on the external and cut surfaces of both lungs. (Fig. 4).

The kidneys showed no macroscopic abnormality. The ureters were normal and patent throughout their length but were pushed laterally by the enlarged para-aortic lymph nodes. The bladder, prostate and urethra appeared normal. The testes were of normal size and were kept intact for fixation and serial section.

Enlarged lymph nodes containing yellow necrotic material were found in the left supraclavicular, mediastinal, para-tracheal, para-aortic areas and along the upper border of the pancreas. The spleen was large $(260 \mathrm{~g}$.) and very soft with a deep purple cut surface. The sternum contained red marrow, the upper half of the femur contained red marrow and the lower half yellow marrow. The cardiovascular and central nervous system showed no significant abnormality.

Macroscopic diagnosis: Carcinomatosis, ? Choriocarcinoma.

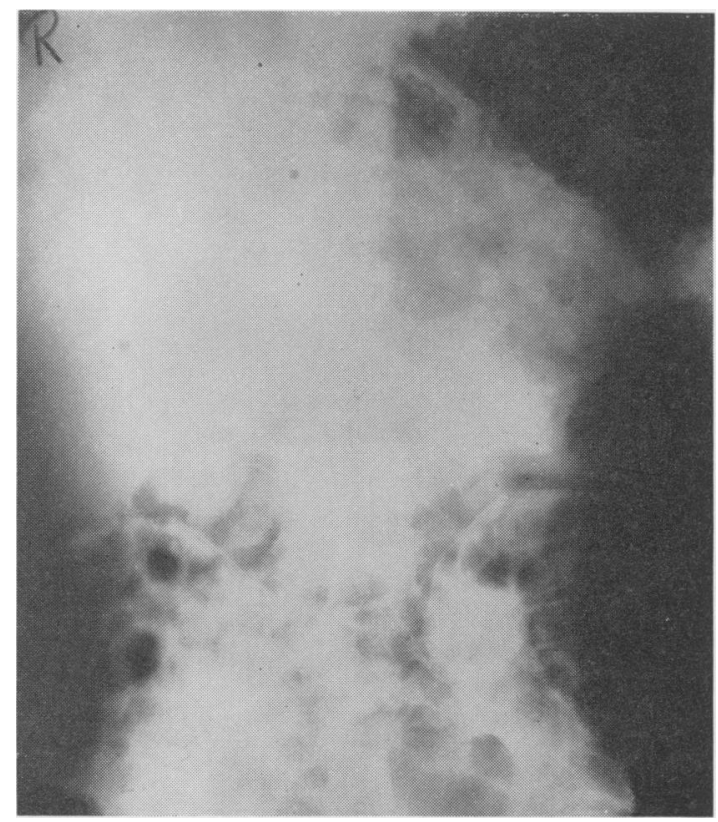

FIG. 2-Portable film of abdomen to show gas containing cavity in upper abdomen.

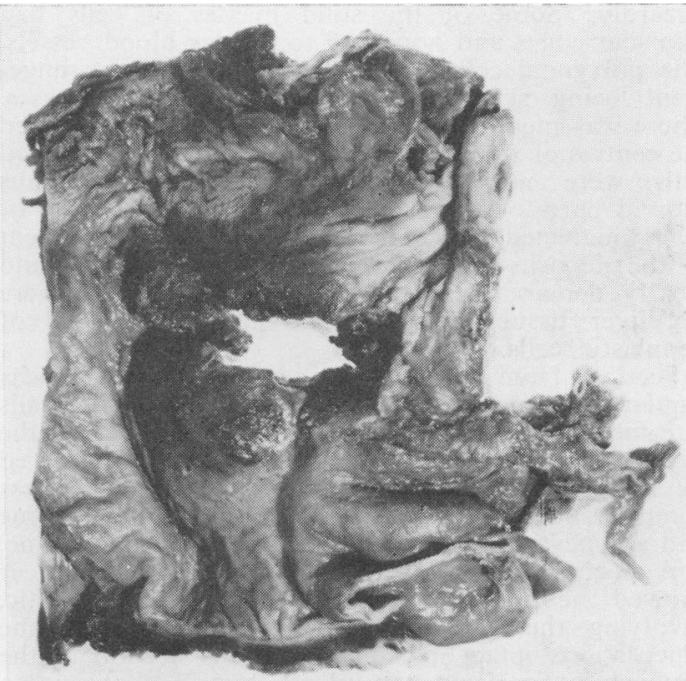

Fig. 3-Posterior wall of stomach showing ragged ulcer containing choriocarcinoma.

In view of the above findings urine was collected at necropsy to be tested for chorionic gonadotrophin (Hogben rest).

Histology: Deposits of a pleomorphic malignant neoplasm were found in the liver. Some cells were round or elongated with fairly dark nuclei showing numerous mitoses. Other cells were polygonal with large pale nuclei and conspicuous nucleoli; mitoses 


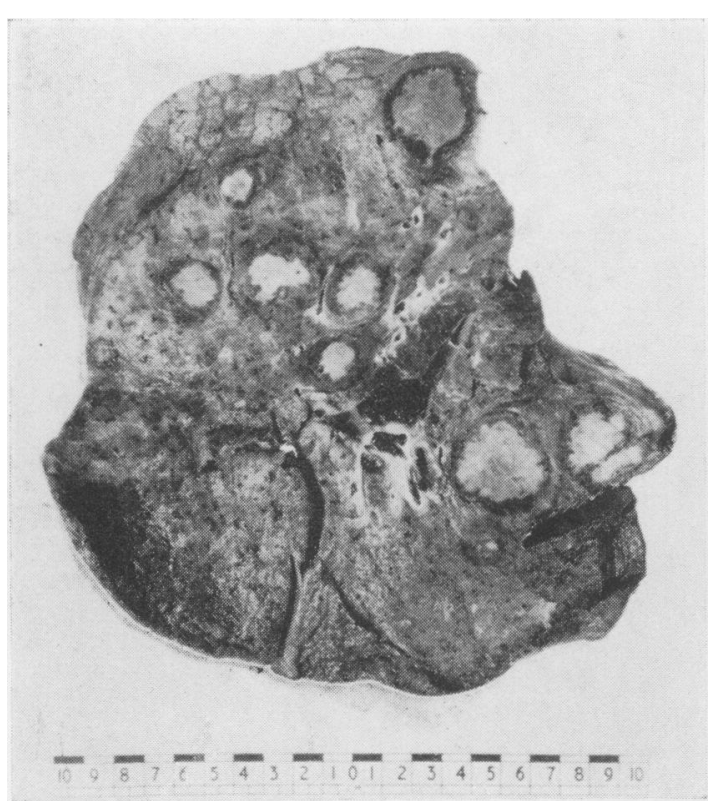

Fig. 4.-Metastatic choriocarcinoma in the lung.

were less common amongst these cells but bizarre giant nuclei were numerous. In some areas the round or elongated cells formed solid islands or trabecular structures but elsewhere they were distributed haphazardly. Some of the solid masses of cells had clear-cut edges and appeared to border blood vessels. The polygonal cells formed no recognisable arrangement being scattered loosely in irregular masses. There was much hæmorrhage within the deposits and the centres of the larger islands of round or elongated cells were necrotic. Leucocytes were numerous around parts of the tumour and also in a section of liver unaffected by tumour. The liver tissue adjacent to the deposits was compressed in some places and clearly demarcated from the tumour but elsewhere the liver tissue was infiltrated by fine strands of neoplastic cells.

Sections from the lungs showed neoplastic deposits similar to those seen in the liver but with cells intermediate between the two types. Some of the deposits had well formed small blood vessels bordered by neoplastic cells. Bizarre giant nuclei were less common but multinucleate cells were present; some had a syncytial appearance being clear cut in outline.

A section of stomach at the site of the ulcer showed neoplasm, much of which was necrotic, involving the full thickness of the wall but the mucosa was intact in some places. A section of the stomach away from the ulcer showed the mucosa and muscle to be intact but necrotic tumour tissue was present deep to this throughout the section.

Neoplastic tissue of fairly uniform cuboidal cells in which acinar structures were conspicuous was seen in the para-aortic lymph node. There was much necrosis and fibrosis in this lymph node and in a lymph node from between the stomach and pancreas.

A section from the middle third of the pancreas showed necrotic material associated with neoplastic cells which did not blend with the autolysed normal pancreatic tissue.

Dilated and hypertrophied ducts but no acini were noted in the breast sections.
No abnormality was discovered in the sections of pituitary gland, kidney, heart, head and tail of pancreas and cervical lymph nodes.

The testes and epididymes were thoroughl examined. They were cut into thin slices after fixation and all the slices were embedded. Seriat $5 / \mu$ sections were prepared and every 40 th sectiō was mounted, stained and examined, thus any lesion greater than $0.02 \mathrm{~cm}$. in diameter was excludect The testes showed normal tubules but no spermato genesis and a moderate increase in interstitial cell $s_{2}^{0}$ no cysts, scars or tumours were seen.

The Pregnancy Diagnosis Laboratory reported Hogben Test-positive, Dilutions-1:10 negatives $1: 100$ negative.

Urinary gonadotrophin assay was carried out by the method used for pituitary hormone (uterine. weight in immature female mice) and a result off 110 HMG units / 24 hrs. was obtained. Loraine (195\& gives the normal range for pituitary gonadotrophis in the male as 5-30 HMG units/24 hrs.

\section{Discussion}

\section{Pathology}

The distribution of the lesions, the naked eye appearance and the majority of the histological sections are all consistent with a diagnosis of choriocarcinoma. Some of the tumoü (especially in the para-aortic lymph nodes) is made up of acini or solid acini of fairly unifognab cuboidal cells. Nevertheless the overall pictires (including hormone assays) is one of chotiocarcinoma, so that the acinar parts are peculiar feature in this case.

Most authors agree that before choriom carcinoma in the male can be considered to bo extragonadal, serial sections of the testis mus? be free of cysts, scars, tumours or male teratoi $\bar{\phi}$ vestiges. However, even if present, the sig? nificance of scars or vestiges is difficult to assess and some authors (Lynch and Blewett: 1953) think that the scars may be the resul of trauma and the small "vestiges" may be secondary to hormonal stimulation from the choriocarcinoma. Azzopardi, Mostofi and Theiss (1961) found scars in the testes of 17 patients with wide-spread choriocarcinoma and related neoplasms. In 13 they found "hæma? toxylin staining deposits" in dilated seminiferous tubules. They interpreted their findings as indicating regression of a primary testiculaw tumour. These deposits were not seen in the present case.

In a recent article Fine, Smith and Pachte (1962) reviewed the world literature on primary extragonadal choriocarcinoma in the male. of 109 reported cases only 18 were wholl acceptable and of these only two had primary abdominal neoplasms. One was in the live (Lochman, 1954) and the other was a combine 
choriocarcinoma and carcinoma of the stomach (Regan and Cremin, 1960). In the present case the two possible sites of the primary tumour are the stomach and mediastinum; in our opinion the more likely site is the stomach; it is rare for a secondary deposit to erode the gastric wall as occurred in this case.

Many theories exist as to the origin of extragonadal choriocarcinoma.

1. Origin from a teratoma (Kantrowitz, 1934).

2. Origin from a "germinal rest" either of toti-potential cells left during the blastula or morula stage of embryonic development or from primordial germ-cell rests, which, on separating from the urogenital ridge in embryo, did not complete the migration to the site of the normal testis.

However, Witschi (1948) does not believe in the somatic differentiation of germ cells.

3. Origin from primitive mesenchymal cells.

4. Origin from a dormant trophoblastic embolus acquired in fotal life.

5. Metaplasia and dedifferentiation of a carcinoma (Pick, 1926) or that embryonal carcinoma is a stage in the development of choriocarcinoma and that embryonal carcinomata themselves arise from multipotential cells (Pierce, 1962).

\section{Radiology}

"Cannon-ball" metastases in the lungs are frequently secondary to malignant disease in the urogenital system; in the male they are most often secondary to seminoma and teratoma of the testis but when associated with gynæcomastia they are virtually diagnostic of choriocarcinoma. Other possible primary lesions which were considered and rejected in this case included osteogenic sarcoma, fibrosarcoma and bronchial carcinoma; multiple staphylococcal abscesses were considered unlikely because of the sharpness of the lung shadows. According to Arandt (1942) the radiological appearances of choriocarcinoma metastases in the lung are quite characteristic, viz., round, largely well-defined densities having in places blurred edges which may merge into pneumonic areas. Such appearances would correspond with the typical pathological findings viz. homogeneous tumours with surrounding zones of infiltration. We have not been able to identify this radiological phenomenon in the present case or in five other cases of choriocarcinoma (including two in males) from our records. It would thus appear that sharplydefined round nodules are the more usual finding.

The displacement of the left kidney and both ureters indicated a retroperitoneal mass (enlarged lymph nodes were found at necropsy). The slight deformity of the calyces could not be regarded as definitely abnormal but further investigation of this was not possible.

The abnormal gas shadows were the most interesting radiological feature and because of them, a gas-forming infection was suspected. The peculiar branching linear shadows could only be explained on the basis of gas in the biliary tree but in the absence of gas in the right lobe of the liver, obstruction of the left hepatic duct had to be postulated. The smaller round accumulations of gas were thought to be in liver tissue. When the collections of gas became confluent it was assumed that the left lobe of the liver had broken down into a large cavity.

The failure of the Gastrografin examination to reveal a gastric perforation which must have been present illustrates a serious limitation of emergency gastro-intestinal examinations, i.e. the distal part of the stomach cannot be visualised unless the patient can be rolled towards his right side and even then the anterior wall of the stomach is not always shown.

\section{Clinical}

Choriocarcinoma in males usually presents between ten and fifty years of age. The onset is often sudden, usually with recurrent hæmoptysis, cough, chest pain or more rarely as a cerebral vascular accident. In extragonadal choriocarcinoma certain sites of origin predominate in different age groups, e.g. origin within the central nervous system tends to be commoner before puberty; mediastinal or retroperitoneal primary tumours occur mainly in young and middle-aged males and a primary origin in the abdominal viscera is more frequent in older patients. (Fine and others, 1962; Jernstrom and MoLaughlin, 1962). Symptoms due to toxæmia and abscess formation in the tumour tissue may be present in addition to those due to local invasion by the tumour. Hormonal disturbances cause loss of libido and impotence and in about $50 \%$ of cases there is unilateral or bilateral gynæcomastia with associated areolar enlargement and pigmentation. The duration of symptoms until the 
time of diagnosis is usually less than three months and death usually occurs in the following three months.

A positive Hogben reaction is obtained only when chorionic gonadotrophin is excreted and a positive Hogben test on urine from a male patient is diagnostic of choriocarcinoma (Dr. B. M. Hobson, personal communication). Midgeley and Pierce (1962) have shown that the syncytiotrophoblast produces the gonadotrophin which Morse, Clark, Macleod, Ernst and Gosse (1962) have shown to cause increased œstrogen output by the testes.

The prognosis of these tumours varies with the extent of gonadotrophin production (Pierce and others, 1959; Pugh, 1962). Although permanent regression in extragonadal choriocarcinoma has not been recorded, temporary regression in testicular choriocarcinoma has followed chemotherapy, in up to $50 \%$ of cases (Li, 1961; Whitmore, 1962). At the present time chemotherapy is the treatment of choice and is discussed by $\mathrm{Li}$ (1961). Regression of the gynæcomastia has followed the removal of a testicular choriocarcinoma (Copeman, 1959).

\section{Summary}

A case of gastric choriocarcinoma in the male with unusual features is described.

We gratefully acknowledge the help and encouragement of Dr. G. A. Gresham and Dr. A. P. Dick, and we would also like to thank Miss B. D. Disbrey who was responsible for the histological preparations. The Department of Medical Photography, Addenbrooke's Hospital and Mr. Patman were responsible for the illustrations.

\section{REFERENCES}

ArandT. J. (1942): Chorionepithelioma in the Male and Female as Observed Roentgenologically, Amer. J. Roentgenol., 47, 591 .

Azzopardi, J. G., Mostofi, F. K., and Theiss, E. A. (1961): Lesions of Testes Observed in Certain Patients with Widespread Choriocarcinoma and Related Tumours, Amer. J. Path., 38, 207.
Copeman, P. W. M. (1959): Chorionepitheliom Teratoma of Testis. Breast Hypertrophy Preceding Palpable Testicular Tumour, Brit. J. Surg., 4 希 203.

Fine, G., SMith, R. W., and Pachter, M. R. (1962) Primary Extragenital Choriocarcinoma in the Mate Subject, Amer. J. med. Ass., 32, 776.

JeRNSTROM, P., and McLaughlin, H. (1962)? Choriocarcinoma of the Thymus, J. Amer. med Ass., $182,147$.

Kantrowitz, A. R. (1934): Extragenital Chorio carcinoma in a Male, Amer. J. Path., 10, 531.

LI, M. C. (1961): Management of Choriocarcinomas and Related Tumours of Uterus and Testis, Meळ Clin. N. Amer., 45, 661.

LOCHMAN, H. (1954): Klinische und Hormonel Boebachtungen-An einem Extra-genitalen Chorio nepitheliom bein Mann, Arch. klin. Chir., 280. 19

LORAINE, J. A. (1958): The Clinical Application of Hormone Assay, London: E. \& S. Livingstone.

LYNCH, M. J. G., and BLEWETT, G. L. (1953) Choriocarcinoma Arising in the Male Mediastinuni Thorax, 8, 157.

Midgley, A. R., and Pierce, G. B. (1962) $\overrightarrow{\dot{\omega}}$ Immunohistochemical Localization of Human Chorionic Gonadotrophin, J. exp. Med., 115, 289

Morse, W. I., Clark, A. F., MacLeod, S. C., ERnST, W. A., and GosSE, C. L. (1962): Urine Estrogen Responses to Human Chorionic Gonadotroph in Men, J. clin. Endocr., 22, 678.

PICK, L. (1926): Bernner Gesellshaft fur Pathơlogische Anatomie und Vergleichende Pathologies Klin. Wschr., 5, 1728.

PIERCE, G. B. (1962): The Pathogenesis of Testictrlar Tumours, J. Urol. (Baltimore), 88, 573.

Pierce, G. B., Dixon, F. J., and Verney, E. (1959) Endocrine Function of a Heterotransplantable Human Embryomal Carcinoma, Arch. Pate (Chicago), 67, 204.

PugH, R. C. B. (1962): Tumours of the Testis $\stackrel{\mathbb{D}}{\mathbb{Q}}$ some Pathological Considerations, Brit. J. Uroh 34, 393.

Regan, J. F., and Cremin, J. H. (1960): Chorion epithelioma of the Stomach, Amer. J. Surg., 10, 22

WhitMORE, W. F. (1962): Some Experiences with Retroperitoneal Lymph Node Dissection an Chemotherapy in the Management of Testis Neoplasms, Brit. J. Urol., 34, 436.

WITSCHI, E. (1948): Migration of Germ Cells of Human Embryos from Yolk Sac to Primitive Gonadal Folds, Carnegie Inst. Wash., 32 (20\%) 69-80. 